\title{
Utilization of Information \& Communication Technologies (ICT) on Scholarly Communication Process of Medical Academics in Sri Lanka
}

\author{
G. D. M. N Samaradiwakara ${ }^{\text {h }}$ \\ BSc (USJP), MLS (Colombo)
}

\begin{abstract}
Sri Lankan Universities of this day and age have entered a phase of radical transformation that is characterized by globalizing with Information and Computer Technologies. This has resulted in bringing up new global issues for scholarly communication processes for academics. However, in this cyber age of ICT, the role of academics should revolutionize towards rapid espousal of them. Especially medical academics, who are at the frontiers of so much new medical technologies and information, should be frontward in integrating the best possible utilization of ICT. This study is an attempt made to investigate how far medical academics utilize ICT in terms of specific scholarly activities for scholarly communication process. The study is compiled with data from questionnaires, supplemented by interviews of 125 medical academics in five universities of Sri Lanka. The final results revealed that the World Wide Web, e-mailing, word processing and presentation packages are the mostly used ICT applications by medical academics. ICT has a significant effect on most scholarly activities and many academics have identified it as a smart facilitator of their work. In this study, recommendations are made to improve infrastructure facilities at the university level.
\end{abstract}

Keywords: $\quad$ scholarly communication, ICT, university academics, ICT utilization

Introduction

Scholarly communication is the process of creating, organizing, evaluating, editing or formatting, distributing, making accessible, archiving, using and transforming information or scholarly works through formal and informal channels locally and globally. Information and Communication Technologies (ICTs) serve as a tool that fosters knowledge society. ICTs provide new and

\footnotetext{
${ }^{\mathrm{h}}$ Senior Assistant Librarian, University of Sri Jayawardhanapura. E-mail: $\underline{\text { mnsamara@sjp.ac.lk }}$
} 
speedy ways of delivering and accessing information, innovative ways of real time communication and so on. Rapid growth, as well as the diffusion of ICT have a strong effect on many aspects of modern scholarly communication process and has begun to evolve a virtual global knowledge society. Thus, the scholarly communication process and the ICT have recognized as essential and active tools of the virtual global knowledge society.

The university academic community can be considered as one of the primary communicator of science and technological innovation of the world. Creation, organization and dissemination of information is a fundamental aspect of an academic career.

Scholarly activities-research-creates a need to spread and share information about the results, methods, new processes and products. The findings are shared and evaluated by colleagues and students. There is a need for both informal and formal communication, both locally and on a world wide scale [Fjallbrant, 1997].

Thus, there is no doubt that the scholarly communication process is in the root of science and technological revolution in human history. University academics contribute to the scholarly communication process involving the knowledge transmission through teaching.

As scholarly communication process becomes increasingly heterogeneous and complex, a hidden powerful driving force that changes working and collaborative patterns of academics came into action. That is the ever developing Information and Communication Technologies (ICTs). ICTs encompass all those technologies that enable the handling of information and facilities different form of communication among human, between human beings and electronic systems. Richard Heeks (1999) defined ICT as, "electronic means of capturing, processing, storing and communicating information. ICTs are based on digital information held as $1 \mathrm{~s}$ and $0 \mathrm{~s}$, and comprise computer hardware and software and networks" [Jankowska, 2004]. 
The fourth information revolution took place with the invention of the digital computer, which had been used as a key tool by the university academics during the last fifty years. In the university environment a decade ago, the use of computers as a teaching/learning and research tool was limited. Academics used computers to prepare or store lecture notes/ handouts and to keep up with administrative activities. As with many other inventions personal computer, had replaced the electric typewriter [Christie, Jaun and Jonsson, 2002]. The computers have become a sophisticated word processor. Lecturers further use computers to improve the presentation qualities of notes or handouts and research outputs.

After barely a decade of development, the power of the personal computer has increased astonishingly [Christie, Jaun and Jonsson, 2002], in line with the blackboard and chalk, textbooks, laboratory equipment, radio, television and the overhead projector, computer mediated teaching, has in most cases merely been used to enhance what would have been done in the classroom in any case [Bates, 2001].

The personal computers had linked to powerful servers and had a capacity to send and receive high quality sound, pictures, diagrams, animation and text. Internet acts as a clearing house of information that are generated and has recognized as an important medium of communication among academics. Thus, there had been an enormous increase in the number of research papers in recent years resulting from international collaboration [Arunachalam, 1999]. From 1981 to 1995, the number of papers with international co-authors rose by $200 \%$, whereas article output grew by only $20 \%$ [NSF, 1998].

Unlike print, television or radio, users of the Internet and computers can instantaneously interact with information, recognize it, reshape it, and respond to it [Logan, 1995]. The revolution in personal computers and the Internet is fuelled by related developments in ICT.

In universities the traditional activities were being altered in modern sophisticated manner through these ICTs. The penetration of ICT in university education has led to speculation about changing paradigms in scholarly 
communication process of academics. ICT had changed teaching, learning as well as core activities of the university relating to production, diffusion and transfer of knowledge. In other words, ICT trend had grave implications on university education or the scholarly activities of the university academics all over the world. Now the scholarly activities of university academics, all most all depend on the ICT.

The current trend of the Sri Lankan university academic community is to adopt ICT in a high level to save time for the convenience of their scholarly work. But, the academic community is being gradually left behind in this case. If they need to be more proactive in the era of ICT, there is a need for professionals who are well equipped for supporting them. The University Grant Commission (UGC) acts as a great supportive body to raise up the ICT infrastructure of universities into a higher level. It has begun to allocate extra funds to obtain hardware and software for development networks in the universities. The effort taken by the UGC to promote ICT has resulted in establishment of ICT facilities to a certain extent in almost all faculties in some of the universities in Sri Lanka.

Although there is wide range of sophisticated facilities with ICT, Sri Lankan academics use only some of them. For this particular study, computing technologies, processing technologies, communication technologies, telecommunication and the Internet represent as ICTs used to communicate, process, create, disseminate, share, store and manage information. Most of the academics in Sri Lankan universities mostly use common computer packages/ programs for their scholarly activities such as creation, processing, store, data analysis and lecture delivering. Some selected for this study are; Word processing packages, Spreadsheet programs, Presentation packages, Page making packages, Statistical packages, Graphic designing packages, EDGs (Electronic Discussion Groups), E-mail (Electronic mail), BBS (Bulletin Board System), WWW (World Wide Web), Telnet and Video conferencing.

Medical Sciences is defined as "scientific disciplines which are basic to the practice of medicine and commonly covered in the pre clinical years of the medical curriculum" (LCSH, 2003).The medical academic community is 
associated with clinical practice and clinical supportive activities, in addition to teaching, learning and research. They also engage in administrative activities. Teaching and learning is a core mission of the academic community in the field of Medical Sciences. Imparting knowledge through teaching is a core mission of medical academics. Lecturing, presentations, evaluation of student performances and conferences are major activities related to teaching. Research is also a major activity of the medical academics. Research related activities that the medical academics are mostly associated with are, publishing, and peer reviewing, and obtaining research grants, participating in workshops / meetings / conferences / professional forums and providing consultations on the area of specialization. Thus, the medical academic community contributes to the scholarly communication process in various capacities, facilitating multidisciplinary collaboration of educational research projects and innovative scientific developments.

Further, the university academics in the field of Medical Sciences have to account for a large fraction, which rapidly runs towards the optimum developments of the National Health Service. Thus, especially the medical academic community has a strong responsibility to adopt and gainmore benefits from ICT for their scholarly communication process, leading to a new scientific revolution.

Medical professionals need high quality information, which should be accessible, authoritative, reliable, accurate and especially current. Another reason for academics to use novel ICT is to keep up date in their field.

Therefore, this study in the field of Medical Science in Sri Lanka, enlightens other fields and the countries in adopting, as well as using ICT for their scholarly communication process.

\section{Objectives of the study}

The main objective of the study is to evaluate the utilization of ICT in scholarly communication process of academics in the universities of Sri Lanka. The specific objectives are; 
To identify and evaluate the scholarly communication process of medical academics.

To find out the ICT utilized by medical academics in scholarly communication process.

To analyze the influence of ICT on scholarly communication process of medical academics.

\section{Research Design}

The Survey method was used to conduct the research. The teaching community in the field of Medical Sciences was the 'population' for this particular study. The common characteristic of the population was that they were 'members of the Faculty of Medicine'. The 'Stratified random sample' was used in sampling, to present all the categories of the population. 'University' and the 'lecturer category' were identified as the criteria for the stratification. The sample was selected to represent each strata proportionately. Twenty five percent $(25 \%)$ of each strata was taken as the sample. The main instrument of the data collection was a questionnaire. The questionnaires were supplemented by interviews in order to overcome the complexities of the questions. The researcher visited all universities except Jaffna to get a good response to the questionnaires by means of interviews. The researcher visited the universities during September - November 2005 and $100 \%$ response rate was achieved in this manner.

The researcher could not get responses from the medical academics in Jaffna for the mailed questionnaires; therefore, the researcher had to eliminate Jaffna from the study.

\section{Results and Discussion}

Out of 131 expected questionnaires administered, 125 responses received amounting to a percentage of $95.42 \%$ Therefore, the overall response rate was satisfactory. The Majority $(51.2 \%)$ of the respondents were senior lecturers. But the gender distribution was not much varied over the respondents. It categorizes as $51.2 \%$ males and $48.8 \%$ females. The majority of respondents $(78.4 \%)$ were from clinical support departments which covers 
Anatomy, Biochemistry, Community \& Family Medicine, Forensic Medicine, Microbiology, Parasitological, Pathology, Pharmacology, Physiology and Medical Education and only Delete $21.6 \%$ respondents delete were from Clinical departments which includes Clinical Medicine, Obstetrics \& Gynecology, Pediatrics, Psychiatry, surgery and Anesthesiology One hundred and sixteen $(92.8 \%)$ respondents use a computer on daily basis for their activities.

\section{Scholarly communication process}

Scholarly communication process of academics mainly comprises of the preparation, communication and feedback of their scholarly activities. In order to evaluate their scholarly communication process, these activities were divided into categories such as; teaching, research and supervision of research, Participation in meetings, workshops/ training programs, and conferences, authorship, as a resource persons in trainings etc.

Sixty six (52.8\%) of medical academics, regardless of their lecturer categories, collects information daily for teaching. $34 \%$ of medical academics conduct at least one research project per year. Male lecturers tend to do more research compared to female lecturers. $39 \%$ of medical academics do not involve in supervision of any students' research. $42 \%$ of medical academics participate in local and international conferences quarterly. $34 \%$ of medical academics write at least one article per year. Medical academics do not engage in consultation work and do not serve as resource persons in workshops etc. They very rarely function as editors or serve in editorial boards

\section{Use of ICTs in scholarly activities}

Respondents use e-mail to perform a large amount of scholarly activities and other personal correspondences. The largest percentage of respondents 118 (95.93\%) used e-mail to be aware of conferences/ meetings/ workshops/ training programs and for finding information on those. A few use e-mail very often for international collaborative research activities.

The survey revealed that almost all medical academics (99\%) used World Wide Web (WWW) for searching information for their teaching, learning and 
research activities. A percentage of 53.78 medical academics used it daily to search for materials on their own authorship. The largest percentage of lecturers $(56 \%)$ used WWW weekly to find information about conferences/ workshops/ training programs. Lecturers and senior lecturers mostly used WWW to find information on conferences and related events.

A very low percentages (20\%) of medical academics used Electronic Discussion Groups, as well as Bulletin Board Systems for their scholarly activities. Only $3.39 \%$ used BBS to collect information on research, publishing and communicating research results. But, some of the interviewees expressed that they used BBS not only to read and submit their articles, but to read news regarding other grants, universities etc.

Medical academic do not use Telnet and the Video Conferencing.

Word processing and presentation were the mostly used computer packages by medical academics. All medical academics used word processing packages in all scholarly activities and used presentation software packages to prepare and deliver lectures. The largest percentage, $76.92 \%$ daily used word processing packages to prepare articles/ abstracts and other work related to authorship. The next larger percentage $73.28 \%$ used it daily in preparing reports/ theses on research activities. $45.08 \%$ of respondents used it weekly in preparing lecture notes and presentations. Almost all the respondents used presentation packages in preparing lecture notes, as well as delivering lectures at their teaching role.

However, the largest percentage of respondents, $65.25 \%$ used presentation packages daily to prepare presentations for conferences/ workshops/training programs.

The majority of medical academics (83\%) used spreadsheets for data analysis purposes. Frequency of using spreadsheets for data analysis differed according to the age groups. Young academics more frequently used spreadsheets.

Only $64 \%$ of medical academics used statistical packages for data analysis. Very few (10\%)_medical academics used page-making software packages and 
graphic design packages for their scholarly purposes.

\section{Utilization of ICT and its effect on scholarly activities}

Respondents have indicated that they used electronic communication technologies such as e-mail, WWW, Electronic Discussion Groups (EDGs), and Bulletin Board Systems (BBSs) for collecting information on teaching and facilitating as resource persons. The frequencies of using them are shown in Table 1.

Table 1- Frequency of using ICTs for collecting information on teaching

\begin{tabular}{|c|c|c|c|c|c|c|}
\hline $\begin{array}{l}\text { Freq } \\
(\%) \\
\text { ICT }\end{array}$ & Daily & Weekly & Monthly & Six monthly & Never & $\begin{array}{l}\text { Total \& } \\
\text { Missing }\end{array}$ \\
\hline E-mail & $\begin{array}{c}1 \\
(0.82)\end{array}$ & $\begin{array}{c}33 \\
(27.03)\end{array}$ & $\begin{array}{c}26 \\
(21.31)\end{array}$ & $\begin{array}{c}39 \\
(31.97)\end{array}$ & $\begin{array}{c}23 \\
(18.85)\end{array}$ & $\begin{array}{l}\mathrm{N}=122 \\
*=3\end{array}$ \\
\hline WWW & $\begin{array}{c}37 \\
(30.33)\end{array}$ & $\begin{array}{c}57 \\
(46.72)\end{array}$ & $\begin{array}{c}17 \\
(13.93)\end{array}$ & $\begin{array}{c}7 \\
(5.74)\end{array}$ & $\begin{array}{c}4 \\
(3.28)\end{array}$ & $\begin{array}{l}\mathrm{N}=122 \\
*=3\end{array}$ \\
\hline EDG & $\begin{array}{c}1 \\
(0.83)\end{array}$ & $\begin{array}{c}2 \\
(1.65)\end{array}$ & $\begin{array}{c}4 \\
(3.31)\end{array}$ & $\begin{array}{c}17 \\
(14.05)\end{array}$ & $\begin{array}{c}97 \\
(80.17)\end{array}$ & $\begin{array}{l}\mathrm{N}=121 \\
*=4\end{array}$ \\
\hline BBS & & $\begin{array}{c}2 \\
(1.65)\end{array}$ & $\begin{array}{c}4 \\
(3.31)\end{array}$ & $\begin{array}{c}3 \\
(2.48)\end{array}$ & $\begin{array}{c}112 \\
(92.56)\end{array}$ & $\begin{array}{l}\mathrm{N}=121 \\
*=4\end{array}$ \\
\hline
\end{tabular}

According to the above Table, the larger percentage (32\%) of respondents used e-mail semiannually, but used the WWW (46.72\%) weekly for collecting information on teaching. The related percentages were $31.97 \%$ and $46.72 \%$ respectively. Most of the respondents never used EDGs and BBSs in collecting information on teaching. However, $17 \%$ of respondents used EDGs, semi annually and $3.31 \%$ used BBSs monthly for collecting information.

According to the application of log linear models, E-mail, WWW, EDG and BBS were the significant sources for collecting information for teaching, research, and authorship. The frequency of using e-mail, WWW, EDG and BBS separately affected information collection activities relating to teaching, 
as well as authorship. Only the frequency levels of using WWW, EDG and BBS have some effect on collecting information for research. E-mail, WWW, and EDG were the significant resources for finding information on conferences/ workshops/ training sessions and reviewing process.

The statistically significant software packages used in preparing lecture notes/ handouts/ documents for teaching and writing were word processing, presentation, and graphic design packages were main software used for preparing presentations for conferences etc. The frequencies of using those packages were also significant.

Respondents were asked the variety of ICTs used for delivering their lectures/ presentations and the frequencies of usage. They indicated that they used only presentation packages as ICT for delivering purposes.

According to Figure 1, more than half of the respondents $(53.7 \%)$ used presentation packages daily for delivering lectures/ presentations. Now the multimedia projectors in all most all-Medical faculties in Sri Lankan universities replaced the OHPs. Therefore, the lecturers tend to used presentation packages for delivering activities.

More than half of the respondents, $52.07 \%$ used WWW for their literature surveys and research work. Pub Med, free online journals, subscribed online journals were the main on-line services they were associated with. The Frequency of using e-journals for research activities were asked from respondents. The results are given in Figure 2.

Figure shows that the largest percentage of respondents $(28.9 \%)$ used ejournals including subscribed by individuals and universities and free online journals for their literature reviews of researches. Only $22.3 \%$ used them daily.

Most of the respondents did not use Electronic Discussion Groups and the Bulletin Board Systems. Among those who used EDGs, the largest percentage $11.86 \%$ used it six monthly. Only $3.39 \%$ respondents used BBSs monthly for collecting information for research. 


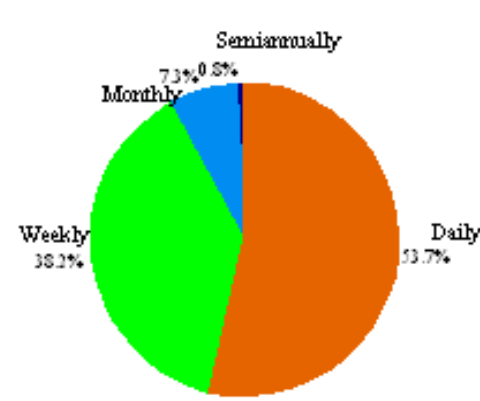

Figure 1- Frequency of using presentation packages

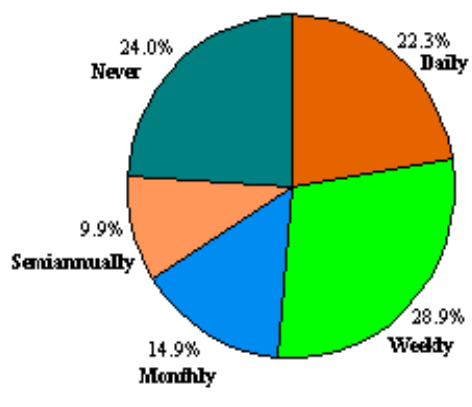

Figure 2 - Frequency of using ejournals for literature surveys

\section{Conclusion}

The incredible advancements in ICT were swiftly changing the scholarly communication scenario and it was a major shift from a traditional ways of the scholarly communication process of university academics.

Medical academics' career comprises of regular teaching, research, participating in meetings, workshops and conferences, authorship and serving as resource persons, in addition to their clinical and clinical support work. They have recognized ICT as a very useful teaching/ learning/ research source, a facility and service. And the frequency of using ICTs has a impact for most of their scholarly activities. However, these services and facilities were not optimally used by medical academics.

\section{Recommendations}

The academics find the ICT facilities provided by Sri Lankan universities are not up to standard. Hence, it is recommended to expand and enhance ICT facilities particularly by providing more improved Internet connections.

The university librarians have a challenge in promoting use of ICT among academics in universities for their information seeking process. Therefore further research has to be carried out in this field.

\section{References}

Albec, B. \& Dingley, B. (2003). What is scholarly communication crisis? Retrieved on June 7, 2004, from 
http://www.lib.umd.edu/CLMD/Faculty/schplarly1.html

Arunachalam, Subbiah (1999). Information knowledge in the age of electronic communication: a developing country perspective...Part I, Retrieved on December 13, 2005, from http://www.bytesforall.org/5TH/arun.htm

Bates, T. (2001). National strategies for e-learning in post secondary education and training: fundamentals of educational planning -70 . Paris: UNESCO.

Best, J.W. and Kahn, J.V. (1992). Research in education. New Delhi: Prentice Hall.

Christie, Michael F., Juan, Andre \& Jonsson, Lars-erik (2002). Evaluating the use of ICT in engineering education. European Journal of engineering education, 27(1), pp.13-20.

Fjallbrant, Nancy (1997). Scholarly communication: historical development and new possibilities, Retrieved on May 25, 2004, from http://www.internet unib ktu It-physics-texts-schoolarlyffig2 gif fileslscolcom.htm

Heeks, Richard (1999). Information \& communication technologies, poverty and development, Retrieved on June 8, 2004, from http://idpm.man.ac.uk/wp/di/di wp05abs.htm

Hughes, Carol A. (2000). Information services for higher education: a new competitive space, Retrieved on June 8, 2004, from http://www.dlib.org/dlib/decembe00/hughes-/12hughes.htm

Jankowska, Maria Anna (2004). Identifying university professors' information needs in the challenging environment of information and communication technologies. The journal of academic librarianship, 30(1), pp. 51-66.

Laurillard, D. (2002). Rethinking university teaching: a framework for the effective use of learning technologies, Retrieved on June 8, 2004, from http://books.google.lk/books.htm

LCSH (2003). Library of Congress: Subject Headings - 26th Edition - Volume III. Washington:_Library of Congress.

Logan, Robert K. (1995). The fifth language: Learning a living in the computer age. Toronto:_Stoddart Publishing.

National Science Foundation (1998). Science and engineering indicators. Washington DC.

Osterwalder, Alexander (2003). ICT in developing countries: a cross-sectoral snapshot, Retrieved on December 1, 2005, from http://inforge.unil.ch/aosterwa 